\title{
Diş hekimliği preklinik eğitimi için sanal gerçeklik ortamında diş modellerinin oluşturulması: Pilot çalışma
}

\section{Creating tooth models in virtual reality environment for dentistry preclinical education: Pilot study}

\author{
Ali Can BULUT'1*i, Orkun SÖNMEZ2
}

${ }^{1}$ Kırıkkale Üniversitesi Diş Hekimliği Fakültesi, Protetik Diş Tedavisi Anabilim Dalı, Kırıkkale/TÜRKiYE ²Ortadoğu Teknik Üniversitesi, Mimarlık Fakültesi, Ankara/TÜRKIYE

Öz

Amaç: Hızla artan teknolojik gelişmeler diş hekimliği eğitimini ister istemez etkilemektedir. Çalışmamızın amacı, çevreleyici sanal gerçeklik ortamında gözlemlenebilecek 3 boyutlu dijital diş modelleri oluşturmak ve bu modellerin diş hekimliği eğitiminde kullanmaya uygunluğunu incelemektir.

Çalışmamızın amacı, çevreleyici sanal gerçeklik ortamında gözlemlenebilecek 3 boyutlu dijital diş modelleri oluşturmak ve bu modellerin diş hekimliği eğitiminde kullanmaya uygunluğunu incelemektir.

Gereç ve Yöntemler: Diş hekimliği pre-klinik eğitiminde kullanılmak üzere pembe mumdan yapılan diş anatomisine uygun diş modelleri model tarayıcısı ile taranarak üç boyutlu dijital diş modelleri oluşturuldu. Bu modeller sanal gerçeklik ortamına aktarıldı. Modeller iki uzman tarafından sanal gerçeklik ortamında incelendi ve 7 seçenekli Likert skalası uygulandı. İstatistiksel yöntem Mann Whitney U ve Bağımsız T testi analizleri yapıldı.

Bulgular: Likert anketi cevaplarında; hiç bir soru için gözlemciler arasında istatiksel olarak anlamlı bir fark görülmedi ( $p>0,05)$. BağımsızT testi sonuçlarına göre; sanal gerçeklik ortamındaki modellerin pembe mumdan yapılan modellere benzediği $(p<0,05)$ fakat anatomik yapı karmaşıklaştıkça kron ve kök şekillerinin daha zor anlaşıldığı görüldü.

Sonuç: Bu çalışmada sanal gerçeklik ortamındaki dijital modellerin pembe mumdan hazırlanan modelleri yansıttığı görülmüştür.

Anahtar kelimeler: Sanal gerçeklik; diş modelleri; pre-klinik eğitimi

Corresponding Author*: Ali Can Bulut, Kırıkkale Üniversitesi Diş Hekimliği Fakültesi, Protetik Diş Tedavisi Anabilim Dalı, Kırıkkale/TÜRKiYE

E-mail: alicanbulut@outlook.com

ODCID: 0000-0002-1586-7403

Gönderim: 17.01.2020 kabul: 10.02.2020

Doi: $10.18663 / \mathrm{tjcl} .676506$ 


\begin{abstract}
Aim: Rapid technological developments inevitably effects dentistry education. The aim of this study is to create three dimensional (3D) digital models of teeth which can be observed in immersive virtual reality environment and further to investigate their validity in terms of dentistry education.
\end{abstract}

Material and Methods: Anatomically appropriate pink wax tooth models which are used in dentistry preclinical education are scanned and three dimensional digital tooth models are created. These models are imported into virtual reality environment. Digital models are examined by two specialists in virtual reality environment with 7-choice Likert scale was applied. Statistical method Mann Whitney $\mathrm{U}$ and Independent $\mathrm{T}$ test analyzes were performed.

Results: Likert survey answers; There was no statistically significant difference between the observers for any questions ( $p>0.05$ ). According to independent $T$ test results; observed that models in virtual reality environment reflect pink wax models $(p<0.05)$ but it is harder to comprehend crown and root shapes in virtual environment for more complex anatomical structures.

Conclusion: It is observed that digital models in virtual reality environments reflect pink wax models.

Keywords: Virtual reality; tooth models; preclinical education

\section{Giriş}

Günümüzde diş hekimliği öğrencileri kişisel hayatlarında ve akademik hayatlarında teknolojinin vazgeçilmez olduğu düşüncesindedirler [1]. Gelişen teknoloji ile birlikte 3 boyutlu grafik modeller, çevrimiçi videolar ve mobil elektronik cihazlar (akıllı telefonlar, tabletler) diş hekimliği eğitiminde yavaş yavaş yerini bulmaktadır. Son dönemde diş hekimliği öğrencilerinin teknolojik cihazların eğitimde yer alması gerekliliğine ve öğrenme performanslarını olumlu yönde etkilediğine dair çalışmalar mevcuttur [2-4].

Sanal gerçeklik (virtual reality - VR) gündelik hayatımızın birçok alanında yerini almaya başlamıştır. Sanal gerçeklik uygulamalarının eğitim, mühendislik, sağlık, iletişim, pazarlama, eğlence ve oyun, mesleki eğitim gibi birçok alanda kullanımı giderek yaygınlaşmaktadır. Sanal gerçeklik; nesne, ortam ve olayların bilgisayar ortamında üç boyutlu modeller yapılarak oluşturulan simülasyonlardır. Kullanıcılar bu simülasyonlar ile görme, işitme ve dokunma gibi duyuları kullanarak etkileşime geçebilmekte, onları kontrol edip deneyimleyebilmektedir. Sanal gerçeklik, sentetik bir ortamda psikolojik bir varlık hissi yaratmaya çalışır [5].

Sanal gerçeklik uygulamalarının bazıları akıllı telefon ortamında akıllı telefon entegreli sanal gerçeklik gözlükleri ile çalıştırıırken, bazıları ise bilgisayar ortamında, bilgisayara bağıı olarak çalışan sanal gerçeklik gözlükleri ile çalıştırılmaktadır. Bilgisayar destekli sanal gerçeklik uygulamaları ve gözlükleri yüksek çözünürlükte görüntü sağlayabildiği ve farklı tipte duyu ve etkileşim biçimlerine (dokunma, uzuv hareketleri, mimikler, vb) hitap eden sanal gerçeklik araçlarının entegrasyonuna olanak verdiği için akıllı telefon ortamındaki sanal gerçeklik uygulamalarına göre kullanıcılarına daha iyi bir deneyim yaşatabilmektedir. Bu şekilde farklı duyu ve etkileşim biçimlerine hitap eden ve kullanıcının ortamda yaptığı hareket ve etkileri eş zamanlıya yakın bir şekilde algılayan ve yine eş zamanlıya yakın bir şekilde sanal ortamdaki alakalı değişiklikleri yapıp, kullanıcıya etkileşimin sonucunu aktarabilen sistemlere çevreleyici sanal gerçeklik (immersive virtual reality) sistemleri denmektedir. Bunu yaparken gerçek dünyanın konum ve yön gibi unsurlarından yararlanırlar. Çevreleyici sanal gerçeklikte deneyimlediğiniz ortam tamamen simüle edilmiş ve yeniden oluşturulmuş, gerçekte var olmayan bir ortamdır. Çevreleyici özelliğinin daha iyi işleyebilmesi ve kullanıı da gerçekçi bir varılık (orada bulunma) hissi yaratılabilmesi için, kullanılan sistemin kullanıc ile etrafındaki fiziksel dünya arasındaki bağlantıyı en aza indirmesi önemlidir. Örneğin sanal gerçeklik gözlükleri kullanıının tüm görüş alanını kaplayıp sadece bilgisayar tarafından üretilen görsellerin görülmesini sağlamalıdır.

Masaüstü sanal gerçeklik uygulamalarının çalıştırılmasında kullanılan başlıca sanal gerçeklik gözlükleri Oculus Rift, HTC Vive ve Microsoft HoloLens gibi ürünlerdir. Sanal gerçeklik uygulamaları sayesinde gerçek hayatta etkileşime geçilmesi, deneyimlenmesi mümkün olmayan nesnelerle etkileşime girebilmek, olay ya da koşulları deneyimleyebilmekmümkündür. Örneğin sanal gerçeklik uygulamalarının tıp eğitiminde kullanılmasıyla öğrenciler anatomi gibi dersleri etkileşimli bir şekilde öğrenme deneyimi elde edilebilmektedir [4-7].

Diş hekimliği alanında güvenlik ilkelerine verilen önemin artması simülasyonların kullanımını yaygınlaştırmaktadır [48]. Diş hekimliği öğrencilerinin klinik uygulamaya geçmeden önce yeterli tecrübe ve beceriye sahip olduklarına emin olabilmek adına simülasyon laboratuvarları ve/veya sanal gerçeklik laboratuarlarına intiyaç vardır [6,7]. Akaltan (2019) yayınladığı makale serisinin pre-klinik eğitimde sanal gerçeklik modelleri ile ilgili bölümünde, gelecekte sanal gerçeklik ile oluşturulan eğitim modellerinin diş hekimliği eğitiminde 
büyük yer alacağını belirtmiştir [8]. Klinik problemlerin teşhisi, görüntülenmesi, tedavisinin planlaması ve tedavisinde dijital teknolojileri kullanmak ve sanal ortamda çalışmak hem harcanan süreyi kısaltmakta hem de tedavi öncesi olası aksilikleri öngörmeye yardımcı olmaktadır [7-9]. Günümüzde, dijitalleşmenin hızla ilerleyip yaşamın bir parçası haline gelmesi ve yapay zekâ alanındaki hızlı ilerlemeyle birlikte bu dijitalleşmenin diş hekimliği eğitiminin de bir parçası olması kaçınılmaz hale gelmektedir $[10,11]$.

Sanal gerçeklik çalışmalarında da kullanılan Likert-tipi soru veya Likert ölçeği geliştirmesi, uygulaması ve değerlendirmesi kolay olduğu için eğitim araştırmalarında tutum, eğilim ve görüş ölçmek amacıyla sıklıkla kullanılmaktadır [12]. Preston ve Colman (2000) araştırmalarında 2, 3 ve 4 seçenekten oluşan ölçeklerin en düşük, 5 ve 6 seçenekten oluşan ölçeklerin orta, 7-10 seçenekten oluşan ölçeklerin ise en yüksek geçerlilik, güvenilirlik ve kullanıcı tercihi değerlerine sahip olduklarını belirtmişlerdir [13]. Sanal gerçeklik çalışmalarında kullanılan anket yöntemi genelde 5 veya 7 seçenekli yapılmaktadır $[12,13]$. Bu çalışmada sanal modeller ile pembe mum modeller arasındaki değerlendirmenin yapılması için 7 seçenekli Likert ölçeği kullanıldığı anket oluşturuldu.

Çalışmamızın amacı a) farklı anatomik yapılara sahip daimi dişlerin modellerini sanal gerçeklik vasıtasıyla oluşturmaya çalışmak, b) sanal modellerin, uygulamakta olduğumuz eğitim modelinde kullanımı açısından mum modellere göre potansiyel avantaj ve dezavantajlarını araştırmaktır.

\section{Gereç ve Yöntemler}

Beş yıldır preklinikte protetik dersi veren bir protez uzmanı tarafından, alt ve üst çenede bulunan dişlerden: santral, kanin, premolar ve molar dişlerin pembe mumdan (Modelling Wax, Dentsply Detrey, İngiltere) modelleri gerçek boyutlarının 3 katı büyüklüğünde hazırlandı (Tablo 1).

\begin{tabular}{l|l|l}
\hline \multicolumn{2}{l}{ Tablo 1. Hazırlanan dişlerin boyutları } & \\
\hline $\begin{array}{l}\text { Diş numarası } \\
\text { Makillar santral diş }\end{array}$ & $\begin{array}{l}\text { Gerçek boyutları } \\
10.5 \mathrm{~mm}\end{array}$ & $\begin{array}{l}\text { Hadel boyutları } \\
\text { model }\end{array}$ \\
\hline $\begin{array}{l}\text { Maksiller kanin dişi } \\
\text { Maksiller 1.premolar } \\
\text { dişi }\end{array}$ & $11 \mathrm{~mm}$ & $33 \mathrm{~mm}$ \\
\hline $\begin{array}{l}\text { Maksiller 1.molar dişi } \\
\text { Maksiller 2.molar dişi }\end{array}$ & $8.0 \mathrm{~mm}$ & $25,5 \mathrm{~mm}$ \\
\hline $\begin{array}{l}\text { Mandibular santral } \\
\text { diş }\end{array}$ & $10,5 \mathrm{~mm}$ & $24 \mathrm{~mm}$ \\
\hline $\begin{array}{l}\text { Mandibular kanin } \\
\text { Mandibular }\end{array}$ & $10 \mathrm{~mm}$ & $21 \mathrm{~mm}$ \\
\hline $\begin{array}{l}\text { 1.premolar } \\
\text { Mandibular 1.molar }\end{array}$ & $7.5 \mathrm{~mm}$ & $31,5 \mathrm{~mm}$ \\
\hline
\end{tabular}

Diş modellerinin taranması amacıyla öncesinde yüzeyi tarayıcı spreyi ( LaborO-Spray S\&SScheftner, Almanya) ile kaplandı. Modeller Kırıkkale Üniversitesi Diş Hekimliği Fakültesinde bulunan 2 kameralı, kırmızı renk lazer ışığı özellikli, 10 mikron hata payına sahip, 1, 3 megapixel çözünürlükteki model tarayıcısı ( 3Shape D700, Copenhagen, Danimarka) ile dijital ortama aktarıldı. Bilgisayar ortamına kaydedilen veriler daha sonra bilgisayar yazılımı (3Shape D700, Copenhagen, Danimarka) sayesinde noktacıklardan oluşan, üç boyutlu olarak her yöne çevrilebilen ve üzerinde düzeltme işlemlerinin yapılabildiği sanal bir modele dönüştürüldü (Şekil 1).

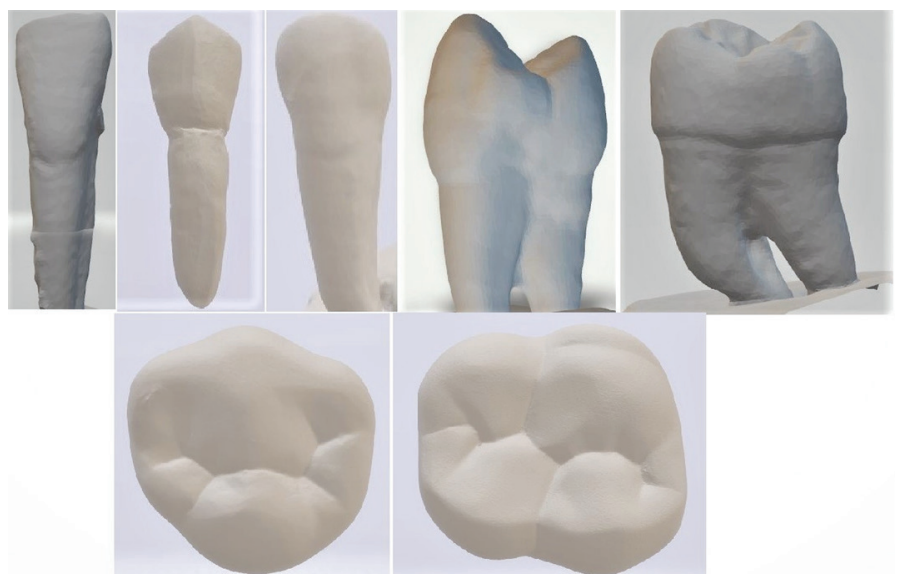

Şekil 1. Pembe mumdan yapılan modellerin bilgisayar ortamında STL dosyasına dönüşmüş halleri.

Elde edilen STL formatlı dosyalar 3 boyutlu modelleme programı Rhinoceros içerisinde dijital içerik yaratma uygulamaları arasında faaliyet kolaylığı sağlayan FBX (Filmbox) formatına dönüştürüldü (Şekil 2).
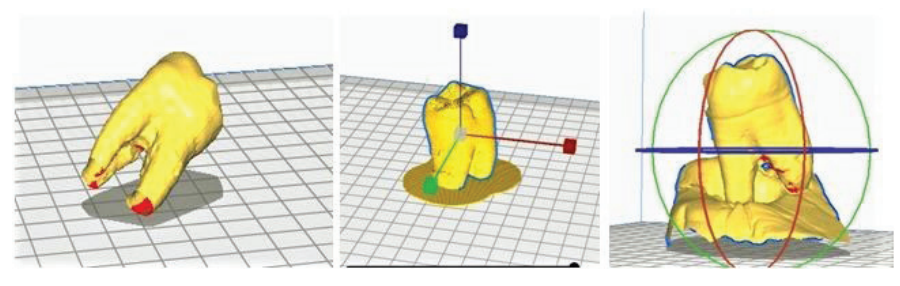

Şekil 2. STL dosyalarının FBX dosyasına dönüştürülmesi.

Dosyalar bu haliyle Unity isimli oyun motoruna aktarıldı. Oculus Rift sanal gerçeklik gözlüğü ve kontrol kolları ile kullanılabilecek ve deneyimlenebilecek bir uygulama Unity içerisinde oluşturuldu (Şekil 3). Unity programında oluşturulan sanal modeller Oculus Rift sanal gerçeklik gözlüğü ve kontrol kolları sayesinde incelenerek modellerin yüzey kontrolleri yapıldı. Tüm modellerin başarılı bir şekilde 3 boyutlu sanal modelleri oluşturuldu. En az beş yıldır protetik diş tedavisi uzmanlığına sahip iki kişiye; pembe mum modeller ve üç boyutlu sanal modeller (Şekil 4) tesadüfi bir sırayla inceletildi ve kendilerinden 
7 seçenekli Likert skalası kullanılarak hazırlanan 12 sorulu anketi cevaplamaları istendi (Tablo 2). Elde edilen veriler SPSS 22.0 (IBM Corp) istatistik programı kullanılarak Mann Whitney U ve Bağımsız T testi analizleri ile değerlendirildi.

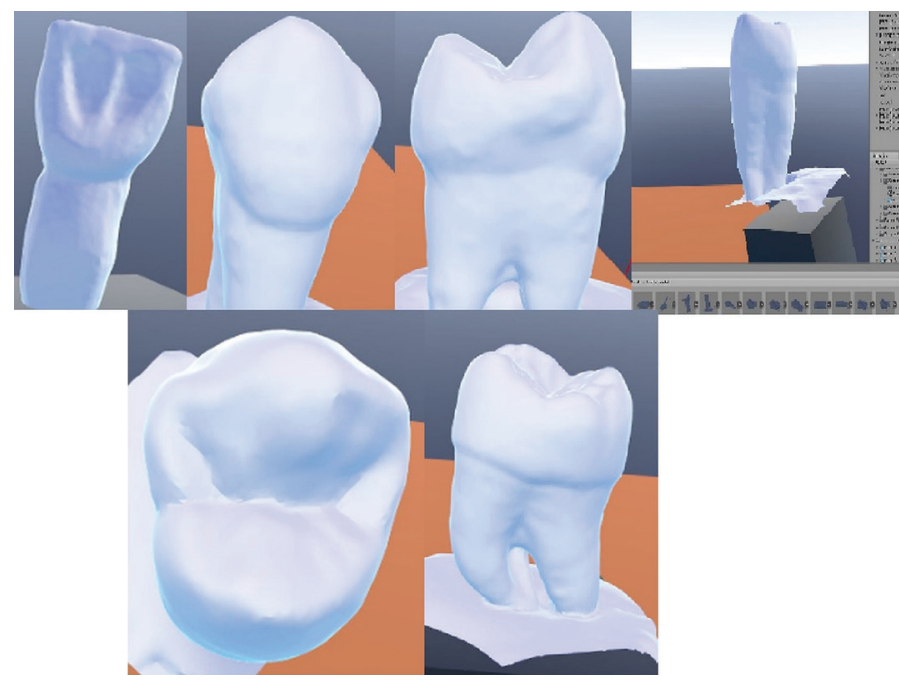

Şekil 3. OculusRift sanal gerçeklik gözlüğü ve kontrol kolları ile kullanılabilecek ve deneyimlenebilecek bir uygulama Unity içerisinde modellerin oluşturulmuş halleri.

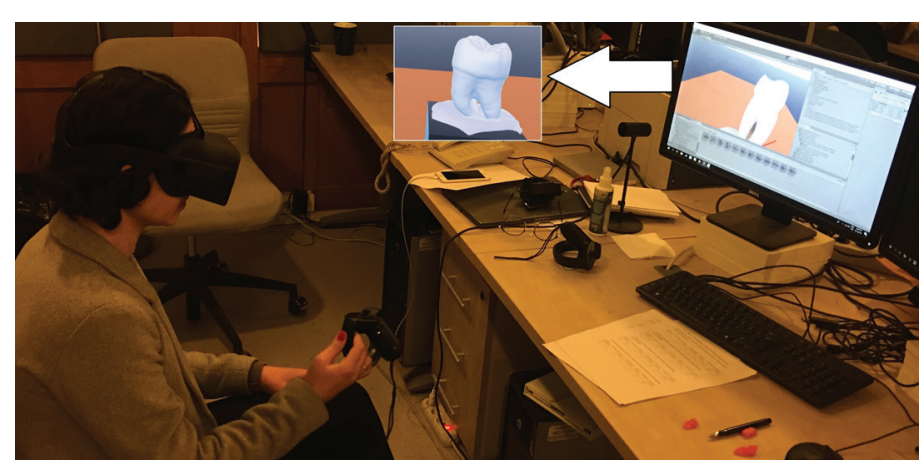

Şekil 4. Sanal modellerin incelenmesi.

\section{Bulgular}

Sanal modelleri ve pembe mumdan yapılan modelleri inceleyen gözlemcilerin anket sorularına verdikleri cevaplar Mann Whitney $U$ testi ile incelendi ve hiç bir soru için gözlemciler arasında istatiksel olarak anlamlı bir fark görülmedi ( $p>0,05)$. Bu sayede gözlemcilerin değerlendirmesinin paralel olduğu görülmüştür (Tablo 3).

Likert puan ortalamalarına soru bazında bakıldığında en düşük ortalama $(5,8333 \pm, 78)$ soru 8'da olduğu görüldü (Tablo 4).

Tüberkülerin anlaşılabilirliği ile ilgili sorulara bakıldığında Soru5'everilen cevaplarınortalaması6,1667 ( $\pm 0,70)$ olarakgörülürken, Soru-5'in sağlamasını yapmak amacı ile sorduğumuz Soru-9 için bulunan ortalama $6,2778( \pm 0,46)$ 'dir. Bu iki soru için bulunan ortalamalar birbirine yakın değerlerdedir. "Sanal modelin tüberkül yapısı, fiziksel modeli birebir yansıtmaktadır" ifadesini içeren Soru-1'in ortalaması ise 6,72 $( \pm 0,46)$ bulunmuştur.
Oklüzyonların anlaşılabilirliği ile ilgili sorulara baktığımızda Soru-6'ya verilen cevapların ortalaması 6,11 $( \pm 0,67)$ olarak görülürken Soru-6'nın sağlamasını yapmak amacı ile sorduğumuz Soru-10 için bulunan ortalama 6,66 $( \pm 0,59)$ 'dır. $\mathrm{Bu}$ sorular için bulunan ortalamalar birbirine yakın değerlerdedir. "Sanal modelin oklüzyonları, fiziksel modeli birebir yansıtmaktadır" ifadesini içeren Soru-2'nin ortalaması ise $6,66( \pm 0,48)$ bulunmuştur.

Kronların anlaşılabilirliği ile ilgili sorulara baktığımızda Soru-7'ye verilen cevapların ortalaması 5,94 $( \pm 0,63)$ olarak görülürken Soru-7'nin sağlamasını yapmak amacı ile sorduğumuz Soru-11 için bulunan ortalama 6,77 $( \pm 0,59)^{\prime}$ dir. Bu sorular için bulunan ortalamalar arasında fark görülmektedir $(p<0,05)$. "Sanal modeldeki kronlar, fiziksel modeli birebir yansıtmaktadır" ifadesini içeren Soru-3'ün ortalaması 6,77( $\pm 0,42)^{\prime}$ dir.

Kök anlaşılabilirliği ile ilgili sorulara baktığımızda Soru-8'e verilen cevapların ortalaması 5,83 $( \pm 0,78)$ olarak görülürken Soru-8'in sağlamasını yapmak amacı ile sorduğumuz Soru-12 için bulunan ortalama $6,94( \pm 0,23)^{\prime} d ı r$. Bu sorular için bulunan ortalamalar arasında fark görülmektedir $(p<0,05)$. "Sanal modelin kronları, fiziksel modeli birebir yansıtmaktadır" ifadesini içeren Soru-4'ün ortalaması 6,27 $( \pm 0,89)^{\prime}$ dir.

İlk analize ait bulgular, sanal modeller ile pembe mum modeller arasında kron şekli ve kök şeklinin algılanması açısından bir fark olduğu izlenimi vermiştir. Dolayısıyla modeller anatomik yapılarına göre: kesici diş modelleri, premolar diş modelleri ve molar diş modelleri olarak 3 ana alt gruba kategorize edilip kron ve kök ile ilgili sorulara verilen yanıtlar yeniden incelenmiştir.

Kron anlaşılabilirliği ile ilgili sorulardan Soru-7'ye molar dişler için verilen cevapların ortalaması 5,5 $( \pm 0,54)$, kesici dişler için verilen cevapların ortalaması ise $6,3( \pm 0,48)^{\prime}$ tür. Soru-11'e molar dişler için verilen cevapların ortalaması $6,5( \pm 0,54)$, kesici dişler için verilen cevapların ortalaması ise 6,7 $( \pm 0,48)^{\prime}$ dir. Soru-7 için, gruplar arasında istatistiksel olarak anlamlı bir fark görülürken $(p<0,05)$ Soru-11'de istatistiksel olarak anlamlı bir fark görülmemiştir $(p>0,05)$. Kökün anlaşılabilirliği ile ilgili sorulardan Soru-8'e molar dişler için verilen cevapların ortalaması 5,5( $\pm 0,54)$, kesici dişler için verilen cevapların ortalaması ise $6,3( \pm 0,48)^{\prime}$ tür. Soru-12'ye molar dişler için verilen cevapların ortalaması 6,5 $( \pm 0,54)$, kesici dişler için verilen cevapların ortalaması ise $6,7( \pm 0,48)^{\prime}$ dir. İki grup arasında Soru-8 için istatistiksel olarak anlamlı bir fark görülürken $(p<0,05)$, Soru-12'de anlamlı bir fark görülmemiştir ( $p>0,05)$ (Tablo 5). 
Tablo 2. 7 noktalı Likert anket soruları ve cevap anahtarı

1- Görsel olarak, sanal modelin tüberkül (singulum) yüzeyi fiziksel modeli birebir yansıtmaktadır.

\begin{tabular}{l|l|l|l|l|l}
2 & 3 & 4 & 5 & 6
\end{tabular}

2- Görsel olarak, sanal modelin oklüzal yüzeyi fiziksel modeli birebir yansıtmaktadır

\begin{tabular}{l|l|l|l|}
2 & 3 & 4
\end{tabular}

5

$6 \quad 7$

3- Görsel olarak, sanal modelin kron şekli fiziksel modeli birebir yansıtmaktadır

\begin{tabular}{|l|l|l|l|l}
2 & 3 & 4 & 5
\end{tabular}

6

7

4- Görsel olarak, sanal modelin kök şekli fiziksel modeli birebir yansıtmaktadır

\begin{tabular}{l|l|l|l|}
2 & 3 & 4
\end{tabular}

5

7

5- Görsel olarak, tüberkül (singulum) yüzeyi sanal modelde daha rahat anlaşılıyor.

\begin{tabular}{l|l|l|l|}
1 & 2 & 3 & 4
\end{tabular}

6

$6 \quad 7$

6- Görsel olarak, oklüzal yüzeyi sanal modelde daha rahat anlaşılıyor.

\begin{tabular}{l|l|l|l|l|l|l|}
\hline 1 & 2 & 3 & 5 & 6 & 7
\end{tabular}

7- Görsel olarak, kron şekli sanal modelde daha rahat anlaşılıyor.

\begin{tabular}{l|l|l|l|l|l|l|}
\hline 1 & 2 & 3 & 4 & 5 & 6 & 7
\end{tabular}

8- Görsel olarak, dişin kök şekli sanal modelde daha rahat anlaşılıyor.

\begin{tabular}{l|l|l|l|l|l|l}
2 & 2 & 3 & 4 & 5 & 6 & 7
\end{tabular}

9- Görsel olarak, tüberkül (singulum) yüzeyi fiziksel modelde daha rahat anlaşılıyor.

\begin{tabular}{l|l|l|l|l|l|l|}
1 & 2 & 3 & 4 & 5 & 6 & 7
\end{tabular}

10- Görsel olarak, oklüzal yüzey fiziksel modelde daha rahat anlaşılıyor.

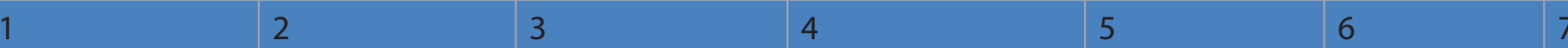

11- Görsel olarak, kron şekli fiziksel modelde daha rahat anlaşılıyor.

\begin{tabular}{l|l|l|l|l|l|l|}
1 & 2 & 3 & 4 & 5 & 6 & 7
\end{tabular}

12- Görsel olarak, dişin kök şekli fiziksel modelde daha rahat anlaşılıyor.

\begin{tabular}{|c|c|c|c|c|c|c|}
\hline 1 & 2 & 3 & 4 & 5 & 6 & 7 \\
\hline $\begin{array}{l}\text { Kesinlikle } \\
\text { Katılmıyorum }\end{array}$ & Katılmıyorum & $\begin{array}{l}\text { Kısmen } \\
\text { Katılmıyorum }\end{array}$ & $\begin{array}{l}\text { Ne katılıyorum } \\
\text { Ne Katılmıyorum }\end{array}$ & $\begin{array}{l}\text { Kısmen } \\
\text { Katılıyorum }\end{array}$ & Katılıyorum & $\begin{array}{l}\text { Kesinlikle } \\
\text { Katılıyorum }\end{array}$ \\
\hline
\end{tabular}

Tablo 3. Gözlemcilerin cevapları arasındaki fark.

\begin{tabular}{|c|c|c|c|c|c|c|c|c|c|c|c|c|}
\hline & Soru 1 & Soru 2 & Soru3 & Soru 4 & Soru 5 & Soru 6 & Soru 7 & Soru 8 & Soru 9 & Soru 10 & Soru 11 & Soru 12 \\
\hline Mann-Whitney U & 36,000 & 31,500 & 40,500 & 40,500 & 20,500 & 18,500 & 25,500 & 28,500 & 36,000 & 38,000 & 36,000 & 22,500 \\
\hline $\begin{array}{l}\text { Asymp. Sig. } \\
\text { (2-tailed) }\end{array}$ & 730 & ,436 & 1,000 & 1,000 & ,077 & ,068 & 190 & 297 & ,730 & ,863 & 730 & 113 \\
\hline
\end{tabular}

Tablo 4. Anket sorularının ortalama değer cetveli

\begin{tabular}{l|l|l|}
\hline Sorular & Ortalamalar & Standart Sapma \\
\hline Soru1 & 6,7222 &, 46089 \\
\hline Soru2 & 6,6667 &, 48507 \\
\hline Soru3 & 6,7778 &, 42779 \\
\hline Soru4 & 6,2778 &, 89479 \\
\hline Soru5 & 6,1667 &, 70711 \\
\hline Soru6 & 6,1111 &, 67640 \\
\hline Soru7 & 5,9444 &, 63914 \\
\hline Soru8 & 5,8333 &, 78591 \\
\hline Soru9 & 6,2778 &, 46089 \\
\hline Soru10 & 6,6667 &, 59409 \\
\hline Soru11 & 6,7778 &, 42779 \\
\hline Soru12 & 6,9444 &, 23570 \\
\hline
\end{tabular}

\begin{tabular}{l|l|l|}
\hline \multicolumn{2}{|l}{ Tablo 5. Anatomik yapıya göre gruplar arası fark } & \\
\hline Model Grupları & Sorular & Sig. (2-tailed) \\
\hline $\begin{array}{l}\text { Kesici diş modelleri- } \\
\text { Premolar diş modelleri- }\end{array}$ & 7 & 0,008 \\
\hline Molar diş modelleri & 8 & 0,44 \\
\hline & 12 & 0,009 \\
\hline
\end{tabular}

\section{Tartışma}

Mobil sağlık teknolojileri ile sanal gerçeklik teknolojilerinin bir arada kullanımı sayesinde sanal gerçeklik teknolojisinin diş hekimliği eğitiminde kullanım alanın artacağı ve daha işlevsel hale geleceği düşünülmektedir [8-10].

Sanal diş modellerinin pembe mum modelleri ile karşılaştırılmasında anket soruları: tüberkül (singulum), oklüzal yüzey, kron şekli ve kök şekli ile ilgili dört kısımdan oluşmaktadır. 
Ortalamalara bakıldığında, "Görsel olarak, ... fiziksel modelde daha rahat anlaşılıyor." önermesini içeren sorular $(9,10,11$ ve 12) arasında tüberkül ile ilgili Soru-9 $(6,27)$ ve oklüzal yüzey ile ilgili Soru-10 $(6,66)$ kron ve kök ile ilgili sorulardan daha düşük değer alırken, "Görsel olarak, ... sanal modelde daha rahat anlaşılıyor." ifadesini içeren sorular (5, 6, 7 ve 8) arasında kron ile ilgili Soru-7 (5.97) kron ve kök şekli ile ilgili Soru-8 $(5,83)$ tüberkül ve oklüzal yüzey ile ilgili sorulardan daha düşük değer almıştır.

Tüberkül ile ilgili sorular için elde edilen değerlere bakıldığında, “... fiziksel modelde daha rahat anlaşılıyor"ve"... sanal modelde daha rahat anlaşılıyor" ifadelerini içeren (sırasıyla) Soru-9 $(6,27)$ ve Soru-5 $(6,16)$ yakın değerler almıştır. Dolayısıyla, tüberkül yüzeylerin hem sanal hem fiziksel modelde birbirine yakın bir derecede anlaşılmış olduğu değerlendirmesi yapılmıştır.

Oklüzal yüzey ile ilgili sorular için elde edilen değerlere bakıldığında, "... fiziksel modelde daha rahat anlaşılıyor" ve "... sanal modelde daha rahat anlaşılıyor" ifadelerini içeren (sırasıyla) Soru-10 $(6,66)$ ve Soru-6 $(6,11)$ yakın değerler almıştır. Dolayısıyla, tüberkül yüzeylerin hem sanal hem fiziksel modelde birbirine yakın bir derecede anlaşılmış olduğu değerlendirmesi yapılmıştır.

Kron şekli ile ilgili sorular için elde edilen değerlere bakıldığında,"... fiziksel modelde daha rahat anlaşılıyor" ve "... sanal modelde daha rahat anlaşılıyor" ifadelerini içeren (sırasıyla) Soru-11 $(6,77)$ ve Soru-7 $(5,94)$ birbirinden istatiksel olarak farklı değerler aldığı ( $p<0.05)$ görülmektedir. Dolayısıyla, kron şeklinin fiziksel modelde incelendiğinde, sanal modele göre daha rahat anlaşılmış olduğu değerlendirmesi yapılmıştır.

Kök şekli ile ilgili sorular için elde edilen değerlere bakıldığında,... fiziksel modelde daha rahat anlaşılıyor" ve "... sanal modelde daha rahat anlaşılıyor" ifadelerini içeren (sırasıyla) Soru-12 $(6,94)$ ve Soru-8 $(5,83)$ birbirinden istatiksel olarak farklı değerler aldığı ( $p<0.05$ ) görülmektedir. Dolayısıyla, kök şeklinin fiziksel modelde incelendiğinde, sanal modele göre daha rahat anlaşılmış olduğu değerlendirmesi yapılmıştır. Molar dişlerin daha karmaşık yapıda olmasından dolayı gruplandırma yapılarak, molar ve kesici dişler arasındaki farka bakmak amacıyla ikinci bir analiz yapılmıştır. Bu analizde; kron şekli ve kök şekli ile ilgili, "... sanal modelde daha rahat anlaşılıyor" ifadesini içeren sorulara bakıldığında molar ve kesici dişler için verilen cevaplar arasında istatistiksel bir fark görülmüştür. Dolayısıyla, katılımcıların sanal gerçeklik uygulamasında molar dişlerin kron ve kök şekillerini anlamakta (fiziksel modeldekine kıyasla) zorlandıkları değerlendirmesi yapılmıştır. Bu fark, anatomik olarak, kesici dişlerden molar dişlere doğru kron ve kök şeklinin daha kompleks bir yapıda olduğu göz önünde alındığında, detayların tarayıcı ile STL dosyası oluştururken ya da sanal gerçeklik programında kaybolmasından kaynaklanmış olabilir.

Bilgisayarlı mikro tomografi sayesinde insan dişlerinden alınan görüntülerin bilgisayar ortamında yeniden modelleme yapıldığı bir çalışmada diş yapısının karmaşık yapısının mümkün olduğunca basitleştirilmesi gerektiği, bu sayede daha düzgün görüntülerin oluşturulabileceği belirtilmiştir [14]. Çürük lezyonlu ve lezyonsuz dişlerin sanal gerçeklikle karşılaştırılmasının yapıldığı bir çalışmada ise sanal gerçeklikle oluşturulan molar dişlerin kök görünümünün (daha gerçekçi görünmesi için) düzeltilmesine ihtiyaç duyulduğu bildirilmiştir [15].

Bu çalışmada da kesici dişler kron yapısı ve kök yapısı açısından sanal modelde molar dişlere göre daha iyi izlenirken; molar dişlerin kron ve kök yapısı pembe mumdan yapılan dişlerde daha iyi izlenmektedir. Bu analiz göz önünde bulundurularak, ileriki çalışmalarda kullanılacak olan modellerin anatomik çeşitliliği ve tarayıcının çözünürlüğü önemli kriterler olarak ele alınmalıdır.

Berman ve ark. 2019'da sanal gerçeklik programı kullanarak bir kütüphane oluşturmaya çalışmışlardır. 109 öğrenciye aşamalı bir sınav uygulamışlardır. 93 tanesi sınavı tamamen bitirebilmiş ve sonrasında sınav ile ilgili anket sorularını tamamlamışlardır. Yaptıkları anket çalışması ile kütüphanenin verimliliğini ölçmüş ve katılımcıların \%50'si sanal gerçeklik kullanmanın kolay olduğunu belirtmişlerdir. Araştırmacılar yaptıkları sanal gerçeklik kütüphanesinin orta düzey başarısın da; Öğrencilerin daha önce böyle bir sanal kütüphane ile çalışmamış olması, sınav süresinin kısa olması ve soru geçişlerinde sistemin takılması olarak göstermektedirler. Çalışmalarında, STL dosyalarından oluşturdukları kütüphaneleri akıllı telefon ortamında deneyimletmişlerdir. Bizim çalışmamız, STL dosyalarıyla bir sanal gerçeklik modeli oluşturup, sanal gerçeklik gözlüğü ve kolları sayesinde kullanıcıyı modelle aynı ortama sokması ile farklılık oluşturmaktadır [6].

Diş hekimliğinde eğitim modellerinin araştırıldığı bir çalışmada 142 diş hekimliği fakültesine online bir anket gönderilmiş ve 62 'si çalışmaya katılmıştır. Avustralya ve Yeni Zelanda'da bulunan diş hekimliği fakültelerinin eğitimlerinde sanal gerçeklik teknolojisi kullanan en muhtemel bölgeler olduğu belirtilmiştir. Sanal gerçeklik uygulamalarının diş hekimliği alanında yavaş ilerlemesinin temel sebepleri olarak maliyet ve eğitim saatlerinin kısıtlı olması öne sürülmüştür [16].

Üretim maliyetinin azaltılması ve kullanıcı dostu daha basit uygulamaların oluşturulması ile sanal gerçeklik uygulamalarının diş hekimliği eğitimindeki yeri artacaktır. 
Böylelikle pre-klinik öğrencileri, sanal gerçeklik ortamında ya da simülatörler aracılığıyla hasta tedavi etmenin prosedürlerini ve diğer önemli unsurlarını öğrenecekleri bir eğitim sistemine kavuşabilirler. Bu sayede temel becerileri güvenli bir şekilde edinebileceklerdir [8-10].

Bakr ve ark. 2014 yılında kendi geliştirdikleri Simodont adlı bir sanal gerçeklik sistemi ile yaptıkları çalışmada sanal gerçeklik uygulamalarının şu aşamada tam olarak geleneksel eğitimin yerine geçemeyeceğini, daha ileri seviye yazılımlara ihtiyaç duyulduğunu bildirmişlerdir [17].

Buchanan ve ark. 2004 yılındaki bir araştırmasında: öğrencilerin sanal gerçeklik simülatörleri ile eğitim aldıklarında, geleneksel pre-klinik laboratuar eğitime kıyasla daha hızlı öğrendiklerini, saat başına daha fazla prosedür uyguladıklarını, aynı yeterlilik seviyelerine ulaştıklarını, bilgisayar aracılığıyla daha fazla değerlendirme istediklerini ve böylece eğitmen-öğrenci değerlendirme süresini azalttıklarını belirtmişlerdir [18]. Uygulamalı lisans diş hekimliği eğitiminde sanal gerçeklik simülatörleri kullanımı objektif izlemeye dayalı değerlendirme üretme ve beceri kazanma oranlarını iyileştirmede etkili olmuştur [19].

Yapılan çalışmalar, laboratuar simülasyonunda daha iyi ve daha etkili öğrenme deneyimleri sağlamanın ve diş hekimliği öğretim programında gelişen teknolojilerin kullanılmasının teknolojik yönden bilgili yeni nesil öğrencilerde öğrenme ve psikomotor becerilerinin gelişmesine yardımcı olduğunu göstermektedir [14,16-21].

2017 yılında diş hekimliğinde teknoloji kullanımı ile ilgili bir çalışmada, günümüzde diş hekimliği eğitim modellerinde sanal gerçeklik ve sanal modellemenin kullanımına başlandığı ve ileriki dönemlerde bu eğitim sisteminin daha da yaygınlaşacağı belirtilmiştir [16]. Bu nedenle, eğitmen ile yüz yüze eğitim süresini kısaltmak, laboratuar eğitim süresini tam olarak kullanabilmek ve öğrencinin güvenle hasta başına geçmeden önce ince motor becerilerini geliştirmek gibi katkılarından dolayı, yapılan işlemlere hızlı bir şekilde geri bildirim sağlayan ve içerisinde öğrencilerin istenen düzeltmeleri yapabildiği sanal gerçeklik uygulamalarıyla harmanlanmış öğrenme tasarımlarının diş hekimliği eğitimine dahil edilmesi gerekir [4,8,13-16,18,22,23].

\section{Sonuç}

$\mathrm{Bu}$ pilot çalışmada pre-klinik eğitimin bir parçası olan diş modellerinin dijital versiyonunu elde edildi. Öğrencilerin farklı diş anatomilerini sanal gerçeklik ortamında gözlemleyebilecekleri diş modellerini elde edilmesinde karşılaşılabilecek problemleri ve dikkat edilmesi gereken unsurlar belirlenmiş oldu. İleriki araştırmalar da farklı diş anatomilerine sahip modellerin sanal gerçeklik ortamında incelenmesinin pre-klinik eğitimindeki etkisinin araştırılması planlanmaktadır.

Maddi destek ve çıkar ilişkisi: Çalışmayı maddi olarak destekleyen kişi/kuruluş yoktur ve yazarların herhangi bir çıkara dayalı ilişkisi yoktur.

\section{Kaynaklar}

1. Blue $\mathrm{C}$, Henson $\mathrm{H}$. Millenials and dental education: utilizing educational technology for effectivete aching. J Dent Hyg 2015; 89: 46-47.

2. Abdelkarim A, Benghuzzi $H$, Hamadain $E$, Tucci $M$, Ford $T$, Sullivan D. US dental students' and faculty members' attitudes about technology, instructional strategies, student diversity, and school duration: a comparative study. J Dent Educ 2014; 78: 614-21.

3. Gadbury-Amyot CC, Purk JH, Williams BJ, Van Ness CJ. Using tablet technology and instructional videos to enhancepre clinical dental laboratory learning. J Dent Educ 2014; 78: 250-58.

4. Khatoon $B$, Hill KB, Walmsley AD. Instant messaging in dental education. J Dent Educ 2015; 79: 1471-78.

5. Slater M. Immersion and the illusion of presence in virtual reality. Br J Psychol 2018; 109: 431-33.

6. Berman H, Karl E, Sherbel J, Sytek L, Ramaswamy V. Validity and user experience in an augmented reality virtual tooth identification test. J Dent Educ 2019; 12: 15-22.

7. Kröger $E$, Dekiff $M$, Dirksen D. 3D printed simulation models based on real patient situations for hands-on practice. Eur J Dent Educ 2017; 21: 119-25.

8. Akaltan F. Diş hekimliğinde preklinik ve klinik eğitim çeşitliliği. Selcuk Dent J 2019; 6: 37-51.

9. Höhne C, Schmitter M. 3D Printed teeth for the preclinical education of dental students Journal of Dental Education 2019; 83: 1100-106.

10. Demirci Ş. Sağlık hizmetlerinde sanal gerçeklik teknolojiler. İnönü Üniversitesi Sağlık Hizmetleri Meslek Yüksek Okulu Dergisi 2018; 6: 35-46.

11. E. Negis. A short history and applications of 3D printing technologies in Turkey. US-Turkey Workshop On Rapid Technologies 2009; 24: 23-30.

12. Bayat B. Uygulamalı sosyal bilim araştırmalarında ölçme, ölçekler ve "likert" ölçek kurma tekniği. Gazi Üniversitesi İktisadi ve İdari Bilimler Fakültesi Dergisi 2014; 16: 1-24. 
13. Preston CC, Colman AM. Optimal number of response categories in rating scales: reliability, validity, discriminating power, and respondent preferences. Acta Psychologica 2000; 104: 1-15.

14. Kato A, Ohno N. Construction of three-dimensional tooth model by micro-computed tomography and application for data sharing. Clin Oral Invest 2009; 13: 43-46.

15. Boer IR, Wesselink PR, Vervoorn JM. The creation of virtual teeth with and without tooth pathology for a virtual learning environment in dental education. Eur J Dent Educ 2013; 17: 191-97.

16. Perry S, Burrow MF, Leung WK, Bridges SM. Simulation and curriculum design: a global survey in dental education. Australian Dental Journal 2017; 62: 453-63.

17. Bakr MM, Massey W, Alexander H. Students' evaluation of a 3DVR haptic device (Simodont). Does early exposure to haptic feed back during preclinical dental education enhance the development of psychomotor skills? Int J Dent Clin 2014; 6: 1-7.
18. Buchanan JA. Experience with virtual reality-based technology in teaching restorative dental procedures. J Dent Educ 2004; 68: 1258-65.

19. Buchanan JA. Use of simulation technology in dental education. J Dent Educ 2001; 65: 1225-31.

20. Towers A, Field J, Stokes C, Maddock S, Martin N. A scoping review of theuse and application of virtual reality in pre-clinical dental education. British Dental Journal 2019; 226: 358-67.

21. Gadbury-Amyot CC, Purk JH, Williams BJ, Van Ness CJ. Using tablet technology and instructional videos to enhance preclinical dental laboratory learning. J Dent Educ 2014; 78: 250-58.

22. Khatoon $B$, Hill KB, Walmsley AD. Instant messaging in dental education. J Dent Educ 2015; 79: 1471-78.

23. Mukhopadhyay S, Kruger E, Tennant M. You Tube: a new way of supplementing traditional methods in dental education. J Dent Educ 2014; 78: 156-71. 